\title{
Prevalence and treatment patterns of dysmenorrhea among female medical students: a questionnaire based study at KIMS, Koppal
}

\author{
Manjunath S. M. ${ }^{1}$, Lakshmipathi B. S. ${ }^{1 *}$, Ravi Kumar S. ${ }^{2}$, V. Srinivasa ${ }^{1}$
}

${ }^{1}$ Department of Pharmacology, ${ }^{2}$ Department of Psychiatry, KIMS, Koppal, Karnataka, India

Received: 30 September 2020

Revised: 05 November 2020

Accepted: 06 November 2020

\section{*Correspondence:}

Dr. Lakshmipathi B. S.,

Email: bslp84@gmail.com

Copyright: (c) the author(s), publisher and licensee Medip Academy. This is an open-access article distributed under the terms of the Creative Commons Attribution Non-Commercial License, which permits unrestricted non-commercial use, distribution, and reproduction in any medium, provided the original work is properly cited.

\begin{abstract}
Background: Dysmenorrhea is a common gynaecological condition which causes physical pain, affects mental wellbeing and quality of life. The aim of the present study was to evaluate the prevalence, severity and the treatment patterns of primary dysmenorrhea among female medical students.

Methods: The present study was a prospective, questionnaire based study conducted during March-April 2020 at KIMS, Koppal. The willing participants were given a time period of 30 minutes to fill the questionnaire.

Results: Among the total of 211 female medical students, 180 students were suffering from dysmenorrhea. Almost $78.3 \%$ of those suffering from dysmenorrhea belonged to the age group of 19-21 years. Most of the students suffering from dysmenorrhea achieved menarche at the age of 13-14 years. A majority (48.8\%) of the dysmenorrhic females had dysmenorrhea of mild degree. $73.8 \%$ of dysmenorrhic females did not seek any medical advice for the management of the symptoms of dysmenorrhea. $76(42.2 \%)$ of the dysmenorrhic participant females missed their classes due to the symptoms of dysmenorrhea. The most favoured drug for the management of the symptoms of dysmenorrhea was the combination of mefenamic acid and dicyclomine (56.8\%). 56.6\% of the subjects utilized pharmacological measures, while the rest $43.3 \%$ utilized non-pharmacological measures for the relief from the symptoms of dysmenorrhea.

Conclusions: The present study recognized that dysmenorrhea is a common menstrual disorder among young females. There should be an effort at mass education of the young females regarding the management of dysmenorrhea.
\end{abstract}

Keywords: Dysmenorrhea, Female medical students, Prevalence, Treatment patterns

\section{INTRODUCTION}

Dysmenorrhea is a common gynaecological condition with painful menstrual cramps of uterine origin. Two types of dysmenorrhea are identified, primary and secondary dysmenorrhea. Primary dysmenorrhea denotes to the menstrual pain without any pelvic pathology. High levels of prostaglandins and their metabolites is the key reason for pain during menstruation. ${ }^{1}$

Though the prevalence rates of dysmenorrhoea differ by age, more than $50 \%$ of women in all age groups experience dysmenorrhoea. The global prevalence rate of dysmenorrhoea is between $50.9 \%$ and $87.4 \% .^{2}$ Parker et al found that $21 \%$ of Australian adolescents experienced severe dysmenorrhoea, with $26 \%$ requiring absence from school. $^{3}$

Various factors which influence the prevalence and severity of dysmenorrhea include younger age, low body mass index, smoking, early menarche, prolonged or aberrant menstrual flow, premenstrual somatic complaints, pelvic infections, psychological disturbance and genetic influence. ${ }^{4}$ 
Most of the women (75.1\%) believe dysmenorrhoea to be a normal part of their lives and that the symptoms will continue to affect their daily life until they near menopause. ${ }^{2,5}$ Dysmenorrhoea causes physical pain, affects mental well-being and quality of life leading to work or school absenteeism and a significant health burden. $^{2}$

Dysmenorrhea disturbs the physical, psychological, and social status of female adolescents. As per the study conducted in India among female medical students who reported dysmenorrhea, $31.67 \%$ and $8.68 \%$ were frequently missing college and classes, respectively. ${ }^{6}$

The management of dysmenorrhea includes both pharmacological and non-pharmacological methods. Non-pharmacological methods include: applying hot compresses, adopting a knee to chest position or drinking hot beverages to relieve the cramps. Common pharmacological treatments adopted include NSAID's and hormones. ${ }^{2}$

A study done in South India disclosed that ibuprofen was taken by $80.95 \%$ of students while a study done in Taiwan and Ghana showed that paracetamol was the most effective strategies in relieving pain from dysmenorrhea. . $^{7,8}$

Since dysmenorrhea affects the quality of life and the study curriculum, its management is vital for medical students. In view of this, the present study was undertaken to evaluate the prevalence, severity and to know the various pharmacological and nonpharmacological measures undertaken by the medical students for relieving dysmenorrhea at our institute of Koppal Institute of Medical Sciences (KIMS), Koppal.

\section{Aims and objectives}

To evaluate the prevalence, severity and the treatment patterns in primary dysmenorrhea among female medical students.

\section{METHODS}

The present study was a prospective, questionnaire based study conducted in the month of March-April 2020 at KIMS, Koppal. The study was initiated after approval from the Institutional Ethics Committee of KIMS, Koppal. The written informed consent was taken from the eligible female medical students who were willing to participate in the study.

The participants were administered a questionnaire with instructions. After going through various research articles on dysmenorrhea, we employed the questionnaire on dysmenorrhea utilized by Gupta et al for this study. ${ }^{1}$ The participants were given a time period of 30 minutes to fill the questionnaire.

\section{Inclusion criteria}

All the female medical students from $2^{\text {nd }}$ year to final year aged between 17 to 24 years who were willing to participate in the study.

\section{Exclusion criteria}

Female medical students who were not willing to participate in the study; female medical students $>25$ years of age; female medical students who were on medications for other illness during this study period including antipsychotics, antidepressants, sedativehypnotics, antispasmodics, corticosteroids etc.

\section{Statistical analysis}

All the duly filled questionnaires were considered for analysis. The collected data was expressed in $\mathrm{n}(\%)$ and in the form of tables, graphs.

\section{RESULTS}

A total of 211 female medical students participated in the study and the data was analysed. Among these female medical students 180 students were suffering from dysmenorrhea, while 31 students did not give any history of dysmenorrhea. Almost $78.3 \%$ of those suffering from dysmenorrhea belonged to the age group of 19-21 years.

Table 1: Demographic and menstruation characteristics.

\begin{tabular}{|c|c|c|c|}
\hline \multirow{2}{*}{ Variables } & \multicolumn{2}{|c|}{ Dysmenorrhea } & \multirow[t]{2}{*}{ Total } \\
\hline & Yes N (\%) & Non N (\%) & \\
\hline \multicolumn{4}{|c|}{ Age (years) } \\
\hline $16-18$ & $09(5)$ & $01(3.2)$ & 10 \\
\hline $19-21$ & $141(78.3)$ & $24(77.4)$ & 165 \\
\hline $22-24$ & $30(16.6)$ & $06(19.3)$ & 36 \\
\hline Total & 180 & 31 & 211 \\
\hline \multicolumn{4}{|c|}{ Age at the time of menarche } \\
\hline$<12$ & $21(11.6)$ & $05(16.1)$ & 26 \\
\hline $13-14$ & $139(77.2)$ & $19(61.2)$ & 158 \\
\hline$>15$ & $20(11.1)$ & $07(22.5)$ & 27 \\
\hline \multicolumn{4}{|c|}{ Regularity of menstrual cycle } \\
\hline Regular & $149(82.7)$ & $25(80.6)$ & 174 \\
\hline Irregular & $31(17.2)$ & $06(19.3)$ & 37 \\
\hline \multicolumn{4}{|c|}{ Duration of menstrual cycle } \\
\hline$<20$ & $02(1.1)$ & 00 & 02 \\
\hline $21-34$ & $158(87.7)$ & $28(90.3)$ & 186 \\
\hline$>35$ & $20(11.1)$ & $03(9.6)$ & 23 \\
\hline \multicolumn{4}{|c|}{ Duration of bleeding in days } \\
\hline$\leq 6$ days & $166(92.2)$ & $30(96.7)$ & 196 \\
\hline$\geq 7$ days & $14(7.7)$ & $01(3.2)$ & 15 \\
\hline \multicolumn{4}{|c|}{ Family history } \\
\hline Yes & $113(62.7)$ & $07(22.5)$ & 120 \\
\hline No & $67(37.2)$ & $24(77.4)$ & 91 \\
\hline
\end{tabular}


Most of the students suffering from dysmenorrhea achieved menarche at the age of 13-14 years. $82.7 \%$ of the dysmenorrhic students had regular menstrual cycles, while only $17.2 \%$ had irregular cycles. A majority i.e. $87.7 \%$ of dysmenorrhic female students had the menstrual cycle of 21-34 days, while $92.2 \%$ had the menstrual bleeding of $\leq 6$ days period. $62.7 \%$ of dysmenorrhic students had a positive family history of dysmenorrhea in either mothers or sisters (Table 1).

Table 2: Factors associated with dysmenorrhea.

\begin{tabular}{|ll|}
\hline Parameter & No. of patients \\
\hline Duration of dysmenorrhea & \\
\hline$<6$ months & $109(60.5)$ \\
\hline$\geq 6$ months & $71(39.4)$ \\
\hline Severity of dysmenorrhea & \\
\hline Mild & $88(48.8)$ \\
\hline Moderate & $67(37.2)$ \\
\hline Severe & $25(13.8)$ \\
\hline Medical advice & \\
\hline Yes & $47(26.1)$ \\
\hline No & $133(73.8)$ \\
\hline Number of days missed at class & \\
\hline A day prior to periods & 11 \\
\hline $1^{\text {st }}$ day & 41 \\
\hline $2^{\text {nd }}$ day & 16 \\
\hline $3^{\text {rd }}$ day & 08 \\
\hline
\end{tabular}

Most of the dysmenorrhic female students (60.5\%) had dysmenorrhea of $<6$ months duration, while $39.4 \%$ had dysmenorrhea lasting for $>6$ months. A majority of the dysmenorrhic females had dysmenorrhea of mild degree $(48.8 \%)$, while $37.2 \%$ had moderate and the rest, only $13.8 \%$ had suffered from severe form of dysmenorrhea. $73.8 \%$ of dysmenorrhic females did not seek any medical advice for the management of the symptoms of dysmenorrhea. $76(42.2 \%)$ of the dysmenorrhic participant females missed their classes due to the symptoms of dysmenorrhea (Table 2).

Table 3: Drugs used for pain management.

\begin{tabular}{|ll|}
\hline Drugs used & N $(\%)$ \\
\hline Mefenemic acid & $35(34.3)$ \\
\hline Mefenemic acid+Dicyclomine & $58(56.8)$ \\
\hline Mefenemic acid+Dicyclomine+Tramadol & $01(0.9)$ \\
\hline $\begin{array}{l}\text { Mefenemic } \\
\text { acid+Dicyclomine+Metronidazole }\end{array}$ & $01(0.9)$ \\
\hline Mefenemic acid+Dicyclomine+Paracetamol & $01(0.9)$ \\
\hline $\begin{array}{l}\text { Mefenemic acid+Dicyclomine+Tranexemic } \\
\text { acid+Ethamsylate }\end{array}$ & $01(0.9)$ \\
\hline Homeopathy & $02(1.9)$ \\
\hline Gynovedan & $01(0.9)$ \\
\hline Regmen uterine syrup & $01(0.9)$ \\
\hline Limicifoga magaphus & $01(0.9)$ \\
\hline Total & 102 \\
\hline
\end{tabular}

The most favoured drug for the management of the symptoms of dysmenorrhea was the combination of mefenamic acid and dicyclomine (56.8\%). Mefenamic acid alone was used by $34.3 \%$ of the participant females for the symptomatic relief of dysmenorrhea. Only 2 $(1.9 \%)$ of the dysmenorrhic females had taken some form of Homeopathy for the treatment, while only single participant had taken gynovedan, regmen uterine syrup and limicifoga magaphus individually for the management of dysmenorrhea (Table 3).

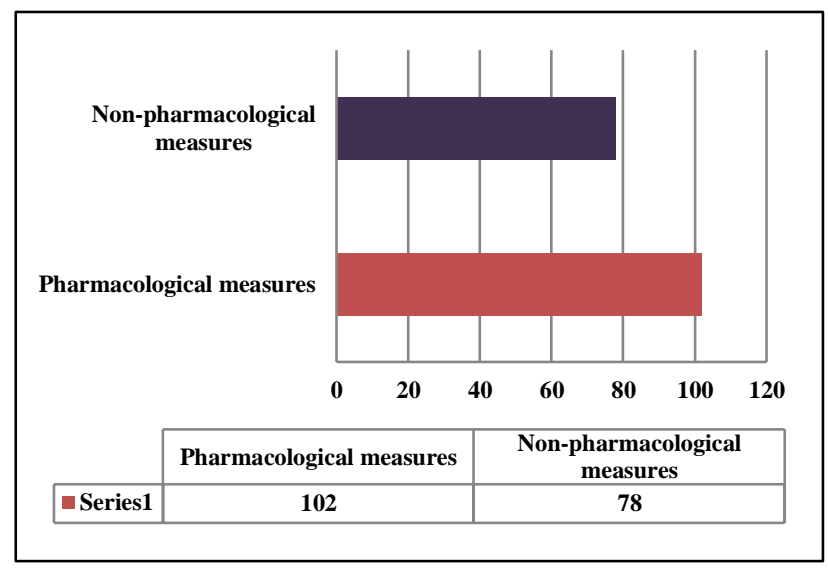

Figure 1: Menstrual pain management behaviour.

Among 180 subjects with dysmenorrhea, 56.6\% utilized pharmacological measures, while the rest $43.3 \%$ utilized non-pharmacological measures for the relief from the symptoms of dysmenorrhea. The non-pharmacological measures adopted by the subjects included hot water bag, drinking hot water alone and with turmeric, consumption of neem leaves juice, chewing of fennel seeds, drinking lemon water, orange juice, mild sweet intake, wearing tight clothes around the waist, eating banana, naturopathy and yoga (Figure 1).

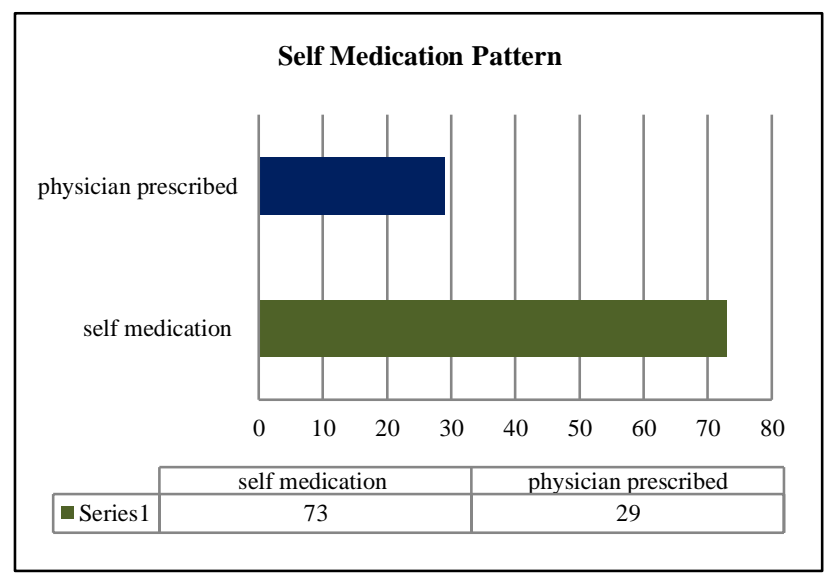

Figure 2: Self-medication by female medical students.

Among 102 dysmenorrhic females, a majority (72\%) opted for self-medication, while the rest $28 \%$ sought the medications prescribed by the physicians for the symptomatic relief of dysmenorrhea (Figure 2). 


\section{DISCUSSION}

Dysmenorrhoea does not only cause physical pain, but it also affects the mental well-being and quality of life, leading to work or school absenteeism and a significant health burden. ${ }^{2}$ It is vital to create awareness about the causes and treatment of dysmenorrhea via the education system and media. Since dysmenorrhea is a common menstrual disorder among young females affecting their quality of life, we undertook this study to assess the prevalence, severity and the treatment patterns of primary dysmenorrhea among female medical students of our Institute KIMS, Koppal. So, the study undertaken would reflect the severity of the problem in our region.

It is estimated that prevalence of dysmenorrhea varies from $20 \%$ to $95 \% .{ }^{9,10}$ In the current study, the prevalence of dysmenorrhea among female medical students was $85.3 \%$ as compared to the prevalence of $84.2 \%$ by Kural et al. ${ }^{11}$ Similar high prevalence rate of $71.8 \%$ was reported by Yesuf et al and $63.7 \%$ by Gupta et al. ${ }^{1,4}$ The reason for the difference in prevalence maybe due to usage of different diagnostic tool or different outlook of the subjects toward menstruation.

In the present study, a majority $77.2 \%$ of females attained the menarche between 13-14 years. These findings are in concurrence with Sherpa et al who reported $78.75 \%$, Kumbhar et al $66.7 \%$ and Gupta et al $64.5 \% .^{1,12,13}$ Most of the females in our study reported mild $(48.8 \%)$ to moderate $(37.2 \%)$ severity of dysmenorrhea. These results are in concurrence with Gupta et al and Omidvar et al. ${ }^{1,14}$ High levels of PGF2 $\alpha$ is the key reason for pain during dysmenorrhea. $\mathrm{PgF} 2 \alpha$ levels are twice higher in dysmenorrhea females than non- dysmenorrhea females during menstruation. ${ }^{14}$

$62.7 \%$ of dysmenorrhic females had a family history of dysmenorrhea in our study. In comparison $74.1 \%$ of subjects had family history as per Kumbhar et al and $53.7 \%$ reported by Sherpa et al. ${ }^{12,13}$ This illustrates that the family history plays a role in the causation of dysmenorrhea.

Prostaglandins play an important role in the inflammation and are the mediators of pain during menstruation. NSAIDS which act by inhibiting the prostaglandin synthesis, play a definitive role in the management of relief of pain during menstruation. In the current study, mefenamic acid alone $(34.3 \%)$ and in combination with anti-spasmodic dicyclomine $(56.8 \%)$ were the most commonly used drugs for relief from dysmenorrhea. These findings are consistent to the results observed by Gupta et al, Marjoribanks et al, and Sugumar et al. ${ }^{1,15,16}$

As per the present study, despite the fact that $56.6 \%$ of dysmenorrhic girls used pharmacological methods for treatment, only $28 \%$ of these sought medical advice. This suggests that, $72 \%$ chose self-medication instead of seeking physician's advice for the management of dysmenorrhea. This is in concurrence with the findings of Gupta et al who reported self-medication amounting to $69.8 \%{ }^{1}$ The high rate of self-medication can be ascribed to the knowledge of medicines/drugs by our medical students and the easy availability of analgesics and antispasmodics for its management. Non-pharmacological methods were used by $43.3 \%$ of the participants. This is in agreement with the results reported by Gupta et al and Sugumar et al. ${ }^{1,16}$

In the present study, nearly $42.2 \%$ of dysmenorrhic females missed their classes due to the troublesome physical symptoms of dysmenorrhea. These findings are in agreement with the study by Gupta et al who reported $35.7 \%$ of dysmenorrhic female medical students had missed their classes because of the physical symptoms of dysmenorrhea. ${ }^{1}$ Most of the female medical students missed the classes on the first day followed by second day. Only few subjects missed their classes during the premenstrual period. Again these findings are similar to the one reported by Gupta et al. ${ }^{1}$

In our study, $28 \%$ of the subjects sought medical advice, while the rest resorted to self-medication. The majority of the students resorted to self-medication because all of the participants are medical students who have the background knowledge of medications and the other reason could be the easy availability of analgesics and anti-spasmodics for the symptomatic relief from dysmenorrhea. Our results are consistent with the findings of Gupta et al who reported that $30.2 \%$ of the female medical students with dysmenorrhea sought medical advice. ${ }^{1}$

The present study was undertaken by us in an effort to highlight the prevalence, the severity and the various treatment modalities adopted by the female medical students of our medical college. One of the limitations of our study is that this research project has been conducted in single medical college. Therefore the sample may not be representative of all the medical colleges of Karnataka.

\section{CONCLUSION}

To conclude, dysmenorrhea is a common menstrual disorder among young females which is associated with physical and emotional symptoms and can also cause class absenteeism as well as affect their quality of life. Various modalities, both pharmacological and nonpharmacological measures are adopted to overcome the symptoms of dysmenorrhea.

\section{Recommendations}

There should be an attempt at mass education to the young females regarding the management of dysmenorrhea wherein, they should be encouraged to adopt non-pharmacological measures for relief from the symptoms of dysmenorrhea and shun the medications/drugs for its management. 
Funding: No funding sources

Conflict of interest: None declared

Ethical approval: The study was approved by the Institutional Ethics Committee

\section{REFERENCES}

1. Gupta S, Kaur S, Sadiq S, Khajuria V. Primary dysmenorrhea: evaluation and treatment pattern among female medical students. Int $\mathbf{J}$ Basic Clin Pharmacol. 2018;7(10):1873-6.

2. Chiu MH, Hsieh HF, Yang YH, Chen HM, Hsu SC, Wang HH. Influencing factors of dysmenorrhea among hospital nurses: a questionnaire survey in Taiwan. BMJ Open. 2017;7:e017615.

3. Chang YT, Chen YC. Menstrual health care behavior and associated factors among female elementary students in the Hualien region. J Nurs Res. 2008;16:8-16.

4. Yesuf TA, Eshete NA, Sisay EA. Dysmenorrhea among University Health Science Students, Northern Ethiopia: Impact and Associated Factors. Int J Reprod Med. 2018;2018:e9730328.

5. Chen CX, Kwekkeboom KL, Ward SE. Beliefs about dysmenorrhea and their relationship to selfmanagement. Res Nurs Health. 2016;39:263-76.

6. Amita S. Prevalence and severity of dysmenorrhea among first and second year female medical students. Indian J Physiol Pharmacol. 2008;52:389-97.

7. Kiran B, Sandozi T, Akila L, Chakraborty A, Meherban, Rani RJ. Study of the prevalence, severity and treatment of dysmenorrhea in medical and nursing students. Int J Pharm Bio Sci. 2012;3(1):16170.

8. Cheng HF, Lin YH. Selection and efficacy of self management strategies for dysmenorrhea in young Taiwanese women. J Clin Nurs. 2011;20:1018-25.

9. Harel Z. A contemporary approach to dysmenorrhea in adolescents. Paediatr Drugs. 2002;4:797-805.
10. Hsu CS, Yang JK, Yang LL. Effect of a dysmenorrheal Chinese medicinal prescription on uterus contractility in vitro. Phytother Res. 2003; $17: 778-83$.

11. Kural M, Nagori NN, Pandit D, Joshi T, Patil A. Menstrual characteristics and prevalence of dysmenorrhea in college going girls. J Fam Med Prim Care. 2015;4:427-31.

12. Sherpa SZ, Devi R, Dangol A, Limbu A, Chettri I, Gurung J, et al. Knowledge regarding dysmenorrhea and its health seeking behavior in colleges of Sikkim. Asian J Nurs Edu Res. 2017;7(4):477-81.

13. Kumbhar SK, Reddy M, Sujana B, Reddy RK, Bhargavi DK, Balkrishna C. Prevalence of dysmenorrhea among Adolescent girls (14-19 years) of Kadapa district and its impact on quality of life: A cross Sectional study. Nat J Community Med. 2011;2(2):265-8.

14. Omidvar S, Bakouei F, Amiri FN, Begum K. Primary dysmenorrhea and menstrual symptoms in indian female students: prevalence, impact and management. Glob J Health Sci. 2016;8(8):53632.

15. Marjoribanks J, Proctor M, Farquhar C, Sangkomkamhang US, Derks RS. Nonsteroidal antiinflammatory drugs for primary dysmenorrhea. Cochrane Database Syst Rev. 2003;2003(4).

16. Sugumar R, Krishnarah V, Channaveera GS, Mruthyunjaya S. Comparison of the pattern, efficacy and tolerability of self-medicated drugs in primary dysmenorrhea: A questionnaire based survey. Indian J Pharmacol. 2013;45(2):180-3.

Cite this article as: Manjunath SM, Lakshmipathi BS, Kumar RS, Srinivasa V. Prevalence and treatment patterns of dysmenorrhea among female medical students: a questionnaire based study at KIMS, Koppal. Int J Basic Clin Pharmacol 2020;9:1844-8. 